\title{
The Conformation and the Aggregation Kinetics of $\alpha$-Synuclein Depend on the Proline Residues in Its C-Terminal Region ${ }^{\dagger}$
}

\author{
Jessika Meuvis, ${ }^{\ddagger}$ Melanie Gerard, ${ }^{\S}$ Linda Desender, ${ }^{\S}$ Veerle Baekelandt," and Yves Engelborghs,, \\ *Laboratory of Biomolecular Dynamics, Katholieke Universiteit Leuven, Celestijnenlaan 200G, B-3001 Leuven, Belgium, \\ ${ }^{\S}$ Laboratory of Biochemistry, Katholieke Universiteit Leuven Campus Kortrijk, Etienne Sabbelaan 53, B-8500 Kortrijk, Belgium, and \\ "Laboratory for Neurobiology and Gene Therapy, Katholieke Universiteit Leuven, Kapucijnenvoer 33, B-3000 Leuven, Belgium
}

Received July 9, 2010; Revised Manuscript Received September 6, 2010

\begin{abstract}
The neuronal protein $\alpha$-synuclein $(\alpha$-syn) plays a central role in Parkinson's disease (PD). The pathological features of PD are the loss of dopaminergic neurons in the substantia nigra pars compacta and the presence of Lewy bodies. The C-terminal domain of $\alpha$-syn is characterized by the presence of 15 acidic amino acids and all five proline residues of the protein (P108, P117, P120, P128, and P138). The aggregation of this natively unfolded protein is accelerated in vitro by FK506 binding proteins (FKBPs) showing peptidyl-prolyl cis-trans isomerase activity. These proteins catalyze the cis-trans conformational change of the X-Pro peptide bond, often a rate-limiting step in protein folding. The acceleration of the folding of $\alpha$-syn by FKBPs may accelerate disease-associated aggregation. To further elucidate the role of the proline residues in the conformation and aggregation of $\alpha$-syn, we constructed several mutants of $\alpha$-syn in which one or more proline residues are mutated to alanine via site-directed mutagenesis. For this purpose, we produced and purified His-WT $\alpha$-syn, a recombinant $\alpha$-syn with a polyhistidine tag (six His residues) and a linker, and a number of Pro-to-Ala mutants. The aggregation kinetics of these mutants and His-WT $\alpha$-syn were studied by turbidity, thioflavin T fluorescence, and CD measurements. We can conclude that mutation of the proline residues to alanine accelerates the aggregation kinetics of $\alpha$-syn while all proline mutants formed fibrils similar to His-WT $\alpha$-syn, as visualized via transmission electron microscopy. We also demonstrate that the accelerating effect of hFKBP12 is abolished via removal of the proline residues from the C-terminus. Finally, we show that the mutant of His $\alpha$-syn with all five proline residues mutated to alanine is more structured (more $\alpha$-helix) than His-WT $\alpha$-syn, indicating the role of the Pro residues as potential helix breakers in the inhibitory conformation of the C-terminus.
\end{abstract}

Aggregation of unstructured proteins is a key element in several neurodegenerative diseases such as Parkinson's disease $(\mathrm{PD})^{1}$ and Alzheimer's disease (AD) (I). The pathological features of PD are a loss of dopaminergic neurons in the substantia nigra pars compacta and the presence of Lewy bodies (LB). LB are intracellular inclusions mainly composed of amyloid fibrils of $\alpha$-synuclein ( $\alpha$-syn) (2). It has been implied that small oligomers rather than fibrils are the toxic species of $\alpha$-syn $(3,4)$. $\alpha$-syn was also genetically linked to PD by the discovery of three point mutations that cause a familial form of PD (5-7). Moreover, it was shown more recently that locus duplication or triplication of the WT $\alpha$-syn gene causes familial forms of PD $(8,9)$.

Finally, the central role of $\alpha$-syn in PD was corroborated experimentally in different animal models in which overexpression leads to formation of neuronal inclusions and motoric symptoms reminiscent of $\mathrm{PD}(10-12)$.

\footnotetext{
This work was financially supported by the Research FoundationFlanders (FWO Project G.0584.06N), the Belgian Federal Science Council (Contract IUAP P6/19), and research funds from the Katholieke Universiteit Leuven (GOA 2006/02 and IOF/KP/07/001).

*To whom correspondence should be addressed: Laboratory of Biomolecular Dynamics, Katholieke Universiteit Leuven, Celestijnenlaan 200G, B-3001 Leuven, Belgium. Telephone: +32 163271 60. Fax: +32 16 3279 74. E-mail: Yves.Engelborghs@fys.kuleuven.be.

${ }^{1}$ Abbreviations: PD, Parkinson's disease; $\alpha$-syn, $\alpha$-synuclein; FKBPs, FK506 binding proteins; PPIase, peptidyl-prolyl cis - trans isomerase; PA, Pro-to-Ala mutants; CD, circular dichroism; ThT, thioflavin T.
}

$\alpha$-syn contains three domains. The $\mathrm{N}$-terminal part (amino acids 1-60) forms $\alpha$-helices when bound to vesicles (13). The central NAC domain (amino acids 61-95) is necessary and sufficient for aggregation $(14,15)$, and the $\mathrm{C}$-terminal domain (amino acids 96-140) contains 15 acidic side chains (10 Glu and 5 Asp residues) but also the only five proline residues of the protein (P108, P117, P120, P128, and P138). Deletion of the $\mathrm{C}$-terminus enhances the aggregation rate of $\alpha$-syn $(16,17)$. Consequently, the $\mathrm{C}$-terminal part is considered as a regulatory part of the protein. Remarkably though, this negatively charged domain is not incorporated into the fibrils $(18,19)$.

$\alpha$-syn is a natively unfolded protein in solution that can adopt an ensemble of conformations without rigid structure but stabilized by long-range tertiary interactions. On the basis of NMR studies, it was suggested that these long-range interactions between the NAC and C-terminal domain inhibit fibril formation (20). It was also shown that Met oxidation strengthens these long-range interaction and leads to the formation of stable nontoxic oligomers $(21)$.

The aggregation of $\alpha$-syn is a nucleation-dependent process with a lag phase, exponential growth phase, and development of a steady state. In the lag phase, an aggregation nucleus, suggested to be a dimer (22), is formed, which is preceded by the formation a partially folded intermediate (23), and followed by oligomer formation (24). In the exponential phase, oligomers grow into protofibrils and finally into mature fibrils (25). 
We have found previously that the aggregation of $\alpha$-syn is accelerated in vitro by FK506 binding proteins (FKBPs) (26). Early aggregate formation, followed with turbidity, was accelerated by the addition of recombinant hFKBP12 in the micromolar range $(26,27)$. Fibril formation (measured by thioflavin $\mathrm{T}$ fluorescence), however, was accelerated in the presence of picomolar to nanomolar and micromolar concentrations of hFKBP12. Addition of the inhibitor FK506 abolished the acceleration of fibril formation. An enzymatically inactive mutant of hFKBP12 (D37L/F99Y) did not have any effect on fibril formation, confirming the importance of the enzymatic activity for the effect of hFKBP12 on $\alpha$-syn fibril formation. However, at micromolar concentrations of the D37L/F99Y hFKBP12 mutant, an acceleration of early aggregate formation was still observed with turbidity, indicating that at these higher concentrations, another type of interaction (e.g., merely binding) was involved.

FKBP12 belongs to the family of immunophilins, enzymes that have a PPIase activity. These proteins catalyze the cis-trans conformational change of a peptidyl-prolyl bond (X-Pro), often the rate-limiting step in protein folding (28). The immunosuppressant FK506 inhibits the peptidyl-prolyl isomerase activity of FKBP12 (29-31).

FKBP12 is strongly expressed in the deep gray matter of the human brain. A first indication that FKBP12 plays a role in PD comes from the observation that its level of expression is increased in a 6-OHDA rodent model of PD as well as in the brain of PD patients $(32,33)$. Also, FKBP12 was found to often colocalize with $\alpha$-syn in LB and with tau in AD brain (34). We have recently reported that overexpression and inhibition of FKBP12 also affects $\alpha$-syn aggregation in neuronal cells and in mouse brain, demonstrating the physiological relevance of our findings (35).

Parvulins and cyclophilins are non-FKBP members of the family of immunophilins. Pin1, a human parvulin, has been implicated in AD (36). Pin1 was also shown to colocalize with $\alpha$-syn in PD brain and to induce $\alpha$-syn aggregation in cell culture (37). These results link peptidyl-prolyl bond isomerization to the pathogenesis of neurodegenerative diseases such as PD and AD.

To further elucidate the role of proline residues in the conformation and aggregation of $\alpha$-syn, we constructed different Pro-to-Ala mutants (PA), as well a mutant with all five proline residues mutated to alanine via site-directed mutagenesis (His- $\mathrm{PA}_{5}$ $\alpha$-syn). The aggregation kinetics of these mutant $\alpha$-syn's were studied with turbidity, thioflavin $\mathrm{T}$ fluorescence, and $\mathrm{CD}$ measurements. We also analyzed the effect of hFKBP12 on the aggregation of His-PA ${ }_{5} \alpha$-syn with turbidity and thioflavin $\mathrm{T}$ fluorescence measurements. Finally, we also compared the secondary structure of His-WT and His-PA $\mathrm{P}_{5} \alpha$-syn with circular dichroism.

\section{EXPERIMENTAL PROCEDURES}

Construction of $\alpha$-syn Expression Plasmids and Purification of Recombinant Protein. The proline mutants of $\alpha$-syn were constructed via site-directed mutagenesis using a two-step polymerase chain reaction (PCR). The presence of the mutations was confirmed by DNA sequencing. His-WT $\alpha$-syn and the HisPA mutant were purified as described previously $(26,27)$. Briefly, BL21(DE3) PLysS Escherichia coli cells were transformed with pRSET B $\alpha$-syn (His-WT or His mutant). Cells were grown at $37^{\circ} \mathrm{C}$ in the presence of $100 \mu \mathrm{g} / \mathrm{mL}$ ampicillin and $30 \mu \mathrm{g} / \mathrm{mL}$ chloramphenicol (Roth, Karlsruhe, Germany). Cells were induced at an $\mathrm{OD}_{600}$ of 0.6 with $1 \mathrm{mM}$ IPTG (Roth) and left shaking for $3 \mathrm{~h}$ at $30^{\circ} \mathrm{C}$. Cells were harvested and suspended in $50 \mathrm{~mL}$ of sonication buffer [20 mM Hepes, $100 \mathrm{mM} \mathrm{NaCl}, 1 \mathrm{mM}$ PMSF, and $0.05 \mathrm{mM}$ EDTA (pH 7.4)]. The lysate was frozen overnight. After sonication $(10 \times 40 \mathrm{~s}$, Branson sonifier 450$)$, the lysate was heated for $45 \mathrm{~min}$ at $65^{\circ} \mathrm{C}$. The cell debris was pelleted by centrifugation at $39100 \mathrm{~g}$ for $30 \mathrm{~min}$ (Sorvall RC-24 refrigerated centrifuge, SLA-1500 rotor). The clear lysate was filtered and subjected to Ni-Ted affinity chromatography (MachereyNagel, Düren, Germany). The fractions that contained $\alpha$-syn were pooled and applied to anion exchange chromatography (Hitrap HP Q, GE Healthcare, Buckinghamshire, U.K.). The column was washed with $20 \mathrm{mM}$ Tris- $\mathrm{HCl}$ and $100 \mathrm{mM} \mathrm{NaCl}$ (pH 8.0). A gradient was applied from $100 \mathrm{mM}$ to $1 \mathrm{M} \mathrm{NaCl}$. All fractions that contained $\alpha$-syn were pooled and desalted on a HiPrep 26/10 desalting column (GE healthcare). The sample was eluted in $20 \mathrm{mM} \mathrm{NH}_{4} \mathrm{HCO}_{3}$ (pH 7.4) and lyophilized (Heto dry winner model DW3, Heto Holten A/S, Allerod, Sweden). The purity was checked via sodium dodecyl sulfate-polyacrylamide gel electrophoresis (SDS-PAGE). WT $\alpha$-syn was expressed and purified as described previously (38). It was previously shown that His-tagged $\alpha$-syn forms the same fibrils as WT $\alpha$-syn $(26,27)$. Although His-WT $\alpha$-syn fibrillates much slower than $\alpha$-syn, we also showed that hFKBP12 accelerates the formation of fibrils of His-WT and WT $\alpha$-syn to the same extent, showing that the presence of the His tag does not substantially affect the acceleration effect of hFKBP12 (Figure 1 of the Supporting Information).

Purification of GST-FKBP12. The pGEX-2TK-FKBP12 expression plasmid was transformed in BL21(DE3) competent cells. The cells were transferred to $5 \mathrm{~mL} \mathrm{LB}$ cultures and grown overnight in the presence of chloramphenicol $(30 \mu \mathrm{g} / \mathrm{mL})$ and ampicillin $(100 \mu \mathrm{g} / \mathrm{mL})$ (Roth). Cells were transferred to a $100 \mathrm{~mL}$ culture and grown overnight. The next morning, cells were transferred to a $2 \mathrm{~L}$ culture and grown to an $\mathrm{OD}_{600}$ of 0.8 . The cells were induced with $1 \mathrm{mM}$ IPTG (Roth) and left shaking for $4 \mathrm{~h}$ at $28^{\circ} \mathrm{C}$. Afterward, cells were harvested by centrifugation and resolubilized in sonication buffer $[20 \mathrm{mM}$ Hepes, $1 \mathrm{mM}$ PMSF, and 1\% Triton X-100 (pH 7.4)]. The pellet was frozen overnight. After sonication, the lysate was filtered with a $0.45 \mu \mathrm{m}$ filter. The lysate was applied to glutathione Sepharose beads (GE healthcare). The beads were washed with $20 \mathrm{mM}$ Hepes, $1 \mathrm{mM}$ PMSF, $100 \mathrm{mM} \mathrm{NaCl}$, and $25 \mathrm{mM} \beta$-mercaptoethanol (pH 7.4). The protein was eluted with $20 \mathrm{mM}$ Hepes, $1 \mathrm{mM}$ PMSF, $100 \mathrm{mM} \mathrm{NaCl}, 25 \mathrm{mM} \beta$-mercaptoethanol, and $10 \mathrm{mM}$ reduced glutathione ( $\mathrm{pH}$ 7.4). The purity was checked with SDS-PAGE.

Peptidyl-Prolyl Cis-Trans Isomerase Activity. The activity of GST-FKBP12 was measured via the method of Kullertz et al. (39). Forty microliters of chymotrypsin $[1 \mathrm{~g} / \mathrm{L}$ chymotrypsin in $35 \mathrm{mM}$ Hepes ( $\mathrm{pH}$ 7.8)] was added to a $4 \mu \mathrm{L}$ sample or $4 \mu \mathrm{L}$ of $35 \mathrm{mM}$ Hepes ( $\mathrm{pH} 7.8$ ) in the blank. The reaction was monitored at $390 \mathrm{~nm}$ after the addition of $400 \mu \mathrm{L}$ of $125 \mathrm{mg} / \mathrm{mL}$ succinimidyl-Phe-Pro-Phe-4-nitroanilide (Bachem). Measurements were performed at room temperature. The data as a function of time were fitted to the equation

$$
y=A_{0}\left(1-\mathrm{e}^{-k_{\mathrm{obs}} t}\right)+B_{0}
$$

to obtain the first-order rate constant $(k)$ of the cis-trans isomerization reaction $\left(A_{0}\right.$ is the extrapolated absorbance at time 


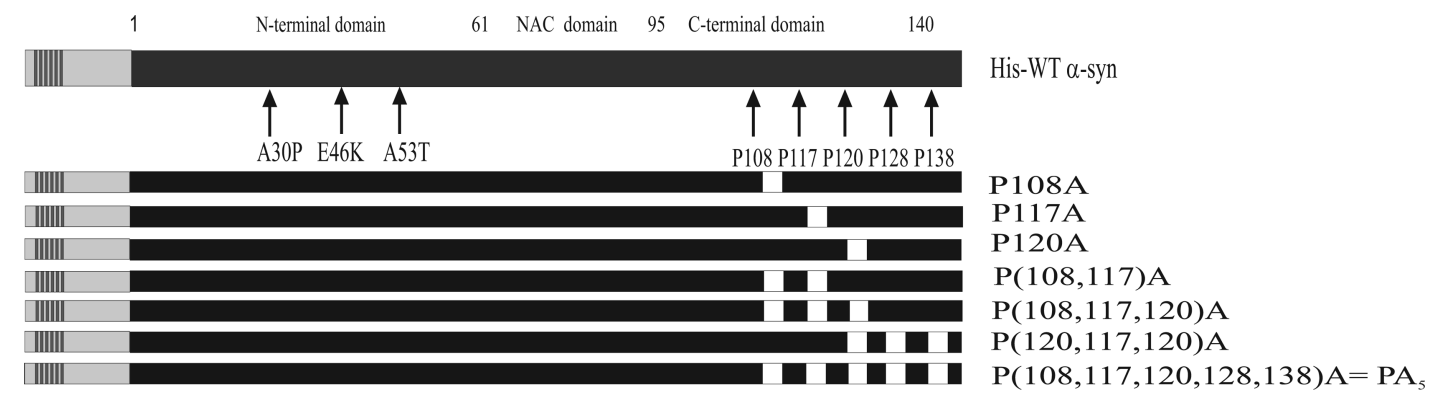

FIgURE 1: Schematic representation of recombinant fusion proteins His-WT $\alpha$-syn and the constructed PA mutants. The clinical mutations are denoted with black arrows. The five Pro residues present in the C-terminus are denoted with gray arrows. The mutated residues in every mutant are colored white. The external tag is colored light gray, and the six histidine residues are colored dark gray.

zero, and $B_{0}$ is the total increase in the magnitude of the absorbance signal). The specific enzymatic activity $\left(k_{\text {cat }} / K_{\mathrm{M}}\right)$ was determined via the equation

$$
\frac{k_{\mathrm{cat}}}{K_{\mathrm{M}}}=\frac{k_{\mathrm{obs}}-k_{0}}{[\text { enzyme }]}
$$

where [enzyme] is the enzyme concentration used, $k_{0}$ is the observed rate constant of the uncatalyzed reaction, $k_{\mathrm{obs}}$ is the observed rate constant in the presence of FKBP12, and $K_{\mathrm{M}}$ is the Michaelis-Menten constant.

Turbidity Measurements. Lyophilized protein was dissolved in $20 \mathrm{mM}$ Hepes, $150 \mathrm{mM} \mathrm{NaCl}$, and $0.02 \% \mathrm{NaN}_{3}(\mathrm{pH}$ 7.4). Small aggregates were removed with the increase in the $\mathrm{pH}$ of the sample to 11 with $0.6 \mathrm{~N} \mathrm{NaOH}$ for $10 \mathrm{~min}$, after which the $\mathrm{pH}$ was lowered again to 7.4 by the addition of $0.6 \mathrm{~N} \mathrm{HCl}(40)$. Samples were centrifuged for $10 \mathrm{~min}$ at $14000 \mathrm{rpm}$ (Eppendorf tabletop centrifuge). Samples were incubated at $37^{\circ} \mathrm{C}$ in a $96-$ well plate (Greiner Bio-one) while being shaken $(\sim 270 \mathrm{rpm})$ in a safire $^{2}$ (Tecan, Mechelen, Belgium). The turbidity was measured every $1000 \mathrm{~s}$ at $350 \mathrm{~nm}$. All experiments were performed at least three times, and representative graphs of these experiments are shown.

Thioflavin T Measurements. Sample preparation was the same as for the turbidity measurements with the exception that $50 \mu \mathrm{M}$ thioflavin $\mathrm{T}$ (Sigma Aldrich) was added prior to the shaking ( $270 \mathrm{rpm})$ at $37^{\circ} \mathrm{C}$. Every $1000 \mathrm{~s}$, the sample was measured by excitation at $446 \mathrm{~nm}$ and fluorescence emission was detected at $482 \mathrm{~nm}$. All experiments were performed at least three times, and representative graphs of these experiments are shown.

Fitting of the Aggregation Curves. All the aggregation curves were fitted to a sigmoid model with four parameters (41) (using Sigmaplot 8.0).

$$
y=y_{0}+\frac{\Delta y}{1+\mathrm{e}^{-k\left(t-t_{1 / 2}\right)}}
$$

where $t_{1 / 2}$ is the half-time of aggregation, $k$ is the rate constant of aggregation determining the steepness of the curve, $\Delta y$ is the total increase in the magnitude of the signal, and $y_{0}$ is the signal at time zero (provided $k t_{1 / 2} \gg 1$ ) .

Circular Dichroism. Sample preparation was the same as for the turbidity measurements. Far-UV CD measurements were performed on a Jasco-800 spectrophotometer (Jasco, Ijsselstein, The Netherlands) in a $0.1 \mathrm{~cm}$ path length cuvette (Hellma, Müllheim, Germany). The protein concentration was $0.2 \mathrm{mg} /$ $\mathrm{mL}$ [20 mM Tris-HCl and $100 \mathrm{mM} \mathrm{NaCl}(\mathrm{pH} 7.4)]$. Spectra were recorded at room temperature, from 195 to $260 \mathrm{~nm}$ with a step size of $1 \mathrm{~nm}$ and a scanning speed of $20 \mathrm{~nm} / \mathrm{min}$. An average of three scans were recorded. Spectra were corrected for the buffer contribution. CD spectra were deconvoluted using the CDSSTR algorithm (42) on Dichroweb (http://dichroweb.cryst.bbk.ac.uk/ html/home.shtml) $(43,44)$.

Transmission Electron Microscopy. Samples for transmission electron microscopy (TEM) were absorbed for 2 min on 300mesh carbon-coated copper Formvar grids and stained for 1 min with $1 \%$ uranyl acetate. Samples were examined with a JEOL JEM 2100 LaB6 electron microscope operating at $200 \mathrm{keV}$.

\section{RESULTS}

Mutation of One or More Proline Residues to Alanine in the $C$-Terminal Part of $\alpha-s y n$ Accelerates Its Aggregation and Fibril Formation. We have shown previously with fluorescence correlation spectroscopy, thioflavin T fluorescence, and turbidity measurements that FK506 binding proteins accelerate the aggregation of His-WT $\alpha$-syn $(26,27)$. This effect was dependent on the concentration of hFKBP12 and on its enzymatic activity, because it was significantly reduced in the presence of the inhibitor FK506 or an enzymatically inactive mutant of hFKBP12 $(26,27)$.

To elucidate the role of the different Pro residues in the aggregation and fibril formation of $\alpha$-syn, the kinetics of aggregation of the constructed PA mutants of His- $\alpha$-syn were studied and compared with those of His-WT $\alpha$-syn using turbidity and ThT fluorescence measurements (Figure 1).

Turbidity measurements can be used to follow the formation of any kind of large aggregates, and turbidity measurements of His-WT $\alpha$-syn show the formation of early, ThT negative aggregates $(26,45,46)$. An example of such aggregation curves measured with turbidity is shown in Figure 2A.

The kinetics of fibril formation of His-WT $\alpha$-syn and the His-PA mutants were also studied with ThT fluorescence. ThT is believed to bind specifically to the crossed $\beta$-structure typical for amyloid fibrils, after which its fluorescence greatly increases (47). Examples of such aggregation curves measured with ThT fluorescence are shown in Figure 2B. The absorbance at $350 \mathrm{~nm}$ or ThT fluorescence of His-WT $\alpha$-syn and the His-PA mutants was measured as a function of time in a 96-well plate under continuous shaking ( $270 \mathrm{rpm})$. The measured aggregation curves of every mutant were fitted with a sigmoidal curve with four parameters (eq 3) to obtain the half-time of aggregation or fibril formation, $t_{1 / 2}$ (in hours). The means and standard deviations of the half-time of aggregation and fibril formation for every mutant were calculated for all measurements compared to the half-time of aggregation (Table 1) or fibril formation (Table 2) of His-WT $\alpha$-syn $(100 \%)$. Turbidity measurements show that the aggregation of His-P108A $\alpha$-syn, His-P117A $\alpha$-syn, His-P120A $\alpha$-syn, His-P(108,117)A $\alpha$-syn, His-P(108,117,120)A $\alpha$-syn, and 

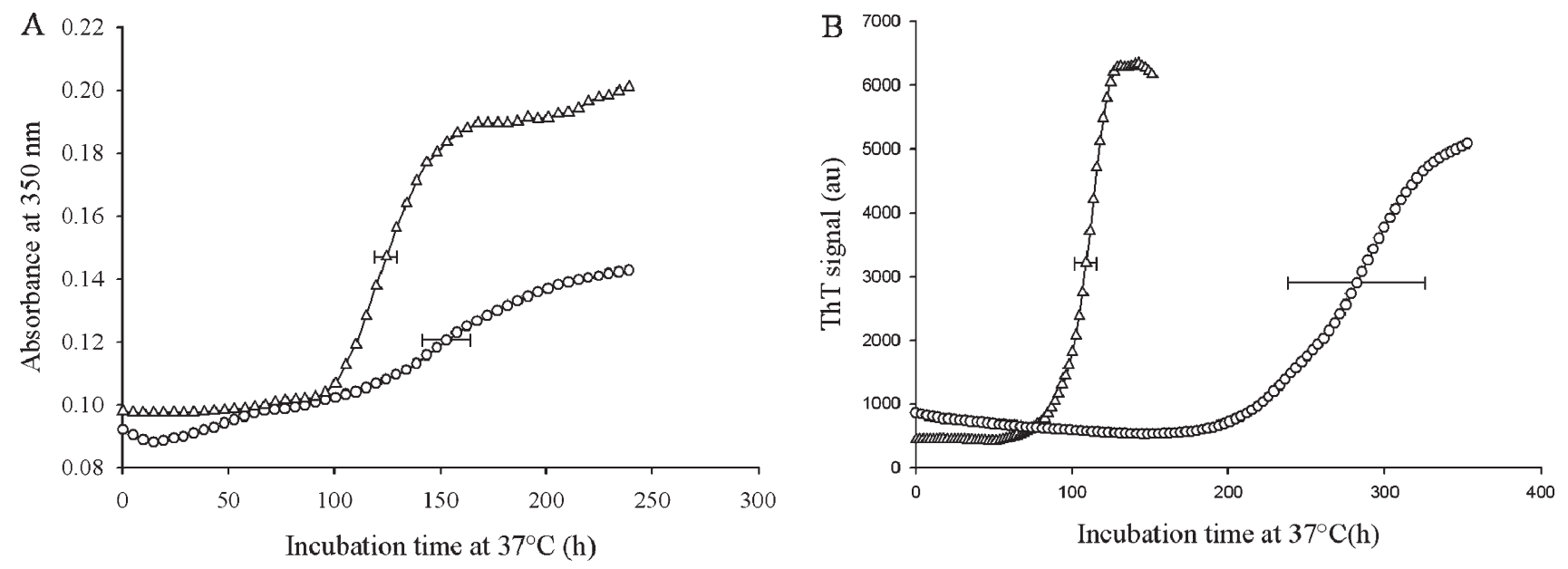

FiguRE 2: Kinetics of aggregation (A) and fibril formation (B) of $\alpha$-syn. $\alpha$-syn (70 $\mu \mathrm{M})$ was incubated at $37^{\circ} \mathrm{C}$ under continuous shaking $(\sim 270 \mathrm{rpm})$ in a Tecan plate reader. (A) Turbidity measurement of aggregation as a function of time for His-WT $\alpha$-syn $(O)$ and $\mathrm{His}-\mathrm{PA} \mathrm{A}_{5} \alpha-\operatorname{syn}(\triangle)$. (B) ThT fluorescence measurement of the time-dependent fibril formation of His-WT $\alpha$-syn $(O)$ and His-PA 5 -syn $(\triangle)$. The horizontal bars represent estimated standard deviations.

Table 1: Half-Times of Aggregation of the PA Mutants and His-WT ${ }^{a}$

\begin{tabular}{lc}
\hline \multicolumn{1}{c}{ protein } & turbidity $t_{1 / 2}(\%)$ \\
\hline His-WT $\alpha$-syn & 100 \\
His-P108A $\alpha$-syn & $77 \pm 7(n=4)$ \\
His-P117A $\alpha$-syn & $66 \pm 6(n=3)$ \\
His-P120A $\alpha$-syn & $71 \pm 6(n=3)$ \\
His-P $(108,117) \mathrm{A} \alpha$-syn & $60 \pm 10(n=7)$ \\
His-P $(108,117,120) \mathrm{A} \alpha$-syn & $77 \pm 9(n=5)$ \\
His-P $(120,128,138) \mathrm{A} \alpha$-syn & $116 \pm 10(n=3)$ \\
His-PA & $\alpha$-syn \\
\hline
\end{tabular}

${ }^{a}$ The half-times of aggregation of the PA mutants are expressed as a percentage of the half-time of aggregation of the control His-WT. The means and estimated standard errors of the mean and the number of measurements $(n)$ are given.

Table 2: Half-Times of Fibril Formation of the His-PA Mutants and His-WT $^{a}$

\begin{tabular}{lc}
\hline \multicolumn{1}{c}{ protein } & ThT $t_{1 / 2}(\%)$ \\
\hline His-WT $\alpha$-syn & 100 \\
His-P108A $\alpha$-syn & $52 \pm 11(n=8)$ \\
His-P117A $\alpha$-syn & $44 \pm 12(n=5)$ \\
His-P120A $\alpha$-syn & $56 \pm 11(n=5)$ \\
His-P $(108,117) \mathrm{A} \alpha$-syn & $54 \pm 8(n=6)$ \\
His-P $(108,117,120) \mathrm{A} \alpha$-syn & $86 \pm 15(n=9)$ \\
His-P $(120,128,138) \mathrm{A} \alpha$-syn & $41 \pm 5(n=5)$ \\
His-PA & $\alpha$-syn \\
\hline
\end{tabular}

${ }^{a}$ The half-times of fibril formation of the His-PA mutants are expressed as a percentage of the half-time of aggregation of the control His-WT. The means and estimated standard errors of the mean and the number of measurements $(n)$ are given.

His-PA $\alpha$-syn is faster than that of His-WT $\alpha$-syn. The kinetics of aggregation of His-P(120,128,138)A $\alpha$-syn, however, are slower than the kinetics of aggregation of His-WT $\alpha$-syn (Figure 3).

From the ThT measurements, we can conclude that the fibril formation of His-P108A $\alpha$-syn, His-P117A $\alpha$-syn, His-P120A $\alpha$-syn, His-P(108,117)A $\alpha$-syn, His-P(120,128,138)A $\alpha$-syn, and His-PA $_{5} \alpha$-syn is faster than that of His-WT $\alpha$-syn. Fibril formation of His-P $(108,117,120) \mathrm{A} \alpha$-syn, however, seems to be only marginally faster than fibril formation of His-WT $\alpha$-syn.
We also visualized the morphology of the aggregates of HisWT $\alpha$-syn and the constructed His-PA $\alpha$-syn mutants with TEM. Samples were taken at the end of the elongation phase. We could show that His-WT $\alpha$-syn and His-PA $5 \alpha$-syn (Figure 4 ) as well as all the His-PA $\alpha$-syn mutants (Figure 2 of the Supporting Information) formed fibrils at the end of the elongation phase, and that these fibrils resemble those found in LB (48).

The Effect of hFKBP12 on the Kinetics of Aggregation of $\alpha$-syn Is Lost When the Five Pro Residues in Its $C$-Terminus Are Mutated. We studied the effect of the enzyme hFKBP12 on His-WT $\alpha$-syn and His-PA ${ }_{5} \alpha$-syn. The activity of the enzyme hFKBP12 was determined using a peptidyl-prolyl bond activity assay. In this assay, the rate constant of the cis-trans isomerization of the peptide bond preceding the Pro residue is determined using the substrate succ-Phe-Pro-Phe-4nitroanilide. This rate constant was determined to be $2.3 \times 10^{6}$ $\mathrm{M}^{-1} \mathrm{~s}^{-1}$, which is consistent with the value of $1.2 \times 10^{6} \mathrm{M}^{-1} \mathrm{~s}^{-1}$ determined by Tradler et al. (49).

We studied the effect of hFKBP12 on the aggregation kinetics of His-WT $\alpha$-syn and His-PA $\mathrm{P}_{5} \alpha$-syn in a concentration range (1 $\mathrm{pM}$ to $1 \mu \mathrm{M}$ ) with turbidity and ThT fluorescence measurements. As controls, His-WT $\alpha$-syn and His-PA $5 \alpha$-syn without the addition of hFKBP12 were used. The measured aggregation curves (turbidity or ThT fluorescence) were fitted with a sigmoidal model with four parameters to obtain the half-time of aggregation for each curve. This half-time of aggregation was normalized against the blank (His-WT or the studied mutant) $(100 \%)(n=3)$. The mean of three measurements was calculated, and the estimated standard error of the mean is shown in the graphs. The accelerating effect of $1 \mu \mathrm{M} \mathrm{hFKBP} 12$ is present for His-WT $\alpha$-syn (Figure 5A). Mutation of all Pro residues to alanine, however, abolishes the acceleration effect of hFKBP12 present in His-WT $\alpha$-syn as measured with turbidity.

The kinetics of fibril formation of His-PA $\mathrm{P}_{5} \alpha$-syn are clearly independent of hFKBP12 concentration (Figure 5B).

The Proline Deficient Mutant Is More Structured Than $H i s-W T \alpha-s y n$. To obtain additional insight into the significance of our findings, we wanted to further study the conformation of the proline mutant compared to His-WT $\alpha$-syn. Therefore, we performed circular dichroism measurements at $\mathrm{pH} 7.4$ to reveal the secondary structure content of His-WT and His-PA 5 
A

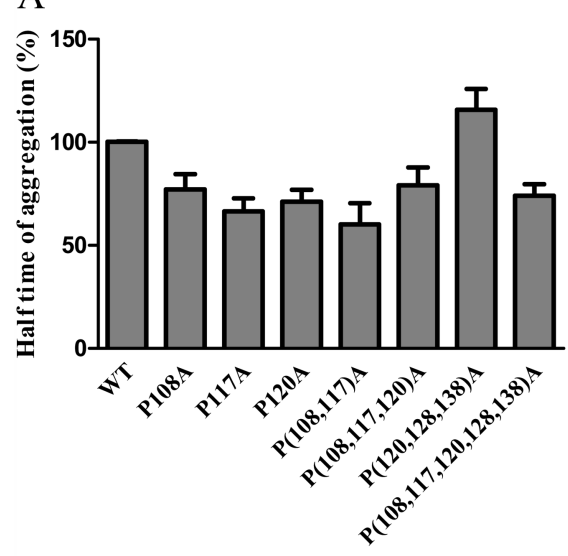

$\mathrm{B}$

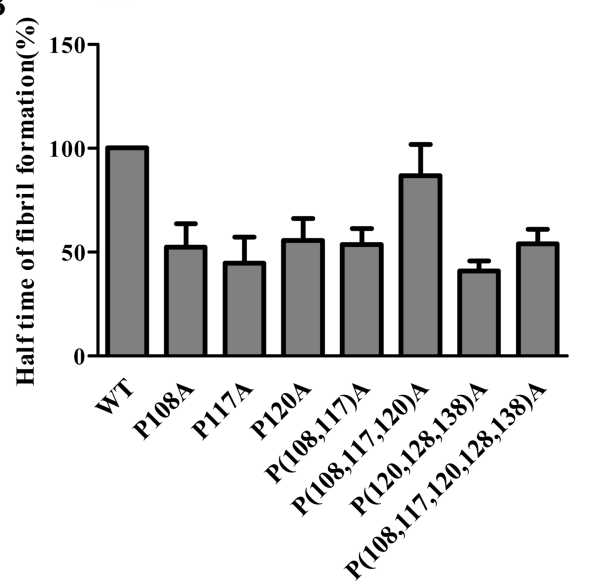

FIGURE 3: (A) Half-times of aggregation obtained from turbidity measurements of His-WT $\alpha$-syn and all the constructed His-PA mutants, after the data had been fit to eq 3 for a sigmoidal model. The half-time of aggregation of the mutants is expressed as a percentage of the half-time of aggregation of the control His-WT $\alpha$-syn. (B) Half-times of fibril formation of His-WT $\alpha$-syn and the His-PA mutants as obtained from ThT fluorescence measurements after the data had been fit to eq 3 . The half-time of aggregation of the mutants is expressed as a percentage of the halftime of aggregation of the control His-WT $\alpha$-syn.
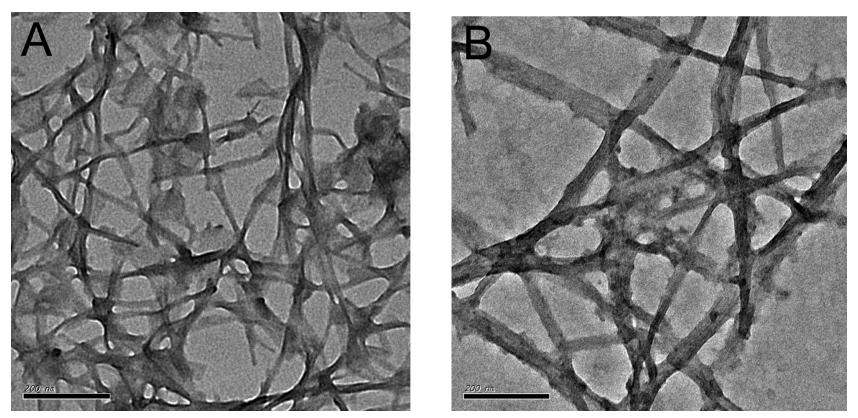

FIgURE 4: TEM images of (A) His-WT $\alpha$-syn and (B) His-PA ${ }_{5} \alpha$-syn incubated at $37{ }^{\circ} \mathrm{C}$ under continuous shaking. The scale bar represents $200 \mathrm{~nm}$. Similar fibrils are observed in all samples.

$\alpha$-syn. The published CD spectra of $\alpha$-syn show a pronounced minimum around $198 \mathrm{~nm}$ (approximately $-14000 \mathrm{deg} \mathrm{cm}^{2}$ $\mathrm{dmol}^{-1}$ ) and a shoulder around $220 \mathrm{~nm}$ (approximately -2000 $\left.\operatorname{deg} \mathrm{cm}^{2} \mathrm{dmol}^{-1}\right)(16,50,51)$ characteristic of a high random coil content (64\%) and some $\beta$-sheet (19\%) (51). Our His-WT $\alpha$-syn shows a minimum that is much less pronounced (at $205 \mathrm{~nm}$ with a mean residue ellipticity of approximately $-2600 \mathrm{deg} \mathrm{cm}^{2} \mathrm{dmol}^{-1}$ ) and the same shoulder at $220 \mathrm{~nm}$ (Figure 6). This is partially due to the contribution of the long His tail (37 extra amino acids) and its potential effect on the structure of $\alpha$-syn. Secondary structure analysis [using the CDSSTR algorithm (42)] shows that His-WT $\alpha$-syn has a higher $\alpha$-helix content (34\%) and lower random coil content $(51.7 \%$, including turns) than $\alpha$-syn. The mutant protein His-PA $\mathrm{PA}_{5} \alpha$-syn has a slightly deeper minimum at $205 \mathrm{~nm}\left(-3250 \mathrm{deg} \mathrm{cm}^{2} \mathrm{dmol}^{-1}\right)$ and a higher shoulder level at $220 \mathrm{~nm}\left(-1500 \mathrm{deg} \mathrm{cm}^{2} \mathrm{dmol}^{-1}\right)$. The proline mutant His-PA ${ }_{5} \alpha$-syn is clearly more structured ( $42 \% \alpha$-helix) but has a lower $\beta$-content (12.6\%) than His-WT $\alpha$-syn according to the numerical analysis.

Aggregation Kinetics Studied with CD Measurements. The changes in the secondary structure of $70 \mu \mathrm{M}$ His-WT and mutant His- $\mathrm{PA}_{5} \alpha$-syn as a function of aggregation time were measured with CD. His-WT $\alpha$-syn and the mutant His-PA $\alpha$-syn were incubated at $37{ }^{\circ} \mathrm{C}[20 \mathrm{mM}$ Tris- $\mathrm{HCl}$ and $150 \mathrm{mM}$ $\mathrm{NaCl}(\mathrm{pH} 7.4)]$ under continuous stirring ( $\sim 500 \mathrm{rpm})$. The spectra were recorded at room temperature.
During the aggregation process, the spectra of the Pro deficient mutant and His-WT $\alpha$-syn are changing with an increase in the ellipticity around $200 \mathrm{~nm}$ and a decrease in the shoulder at $220 \mathrm{~nm}$, indicating an increasing $\beta$-sheet structure content (Figure 7).

His-PA $\mathrm{PA}_{5} \alpha$-syn already shows an increase of $\beta$-sheet after $29 \mathrm{~h}$ in the aggregation process, while His-WT $\alpha$-syn does not show any indication for that even after aggregation for $45 \mathrm{~h}$ (Figure 7B). Thus, the kinetics of $\beta$-sheet formation of the mutant are accelerated compared to those of His-WT $\alpha$-syn. This is in accordance with the results obtained from the turbidity and ThT fluorescence measurements. In conclusion, $\mathrm{CD}$ measurements also demonstrate that the kinetics of $\beta$-sheet formation of the proline deficient mutant $\alpha$-syn are significantly accelerated compared to those of the His-WT protein.

\section{DISCUSSION}

It was reported by our group that hFKBP12 and slyD accelerate the aggregation of $\alpha$-syn in vitro (26), and this accelerating effect proved to be concentration-dependent (27). SlyD and hFKBP12 are enzymes that have a PPIase activity, thus catalyzing the slow cis-trans conformational change of an $\mathrm{X}$-Pro peptide bond. The physiological relevance of these findings was demonstrated by the fact that overexpression and inhibition of hFKBP12 also affect $\alpha$-syn aggregation in neuronal cells and in mouse brain (35).

Role of Pro Residues in the Aggregation Kinetics of $\alpha-s y n$. To further elucidate the role of the Pro residues, several mutants, in which one or more Pro residues were mutated to Ala, were constructed and purified (Figure 1). This is a generally accepted procedure for determining if a Pro residue in a protein is essential for folding $(52,53)$. We have used three methods to study the kinetics of aggregation, i.e., turbidity, ThT fluorescence, and CD measurements. We show that mutation of one or more Pro residues modifies the aggregation kinetics of $\alpha$-syn, because His-P108A, His-P117A, His-P120A, His-P(108,117)A, His- $\mathrm{P}(108,117,120) \mathrm{A}$, and His-PA ${ }_{5} \alpha$-syn aggregate faster than His-WT $\alpha$-syn. Therefore, it appears that mutation of the individual prolines (P108, P117, and/or P120) to Ala increases the rate of aggregation of $\alpha$-syn.

Also, the kinetics of fibril formation, as measured with ThT fluorescence, are accelerated in the mutants His-P108A, 

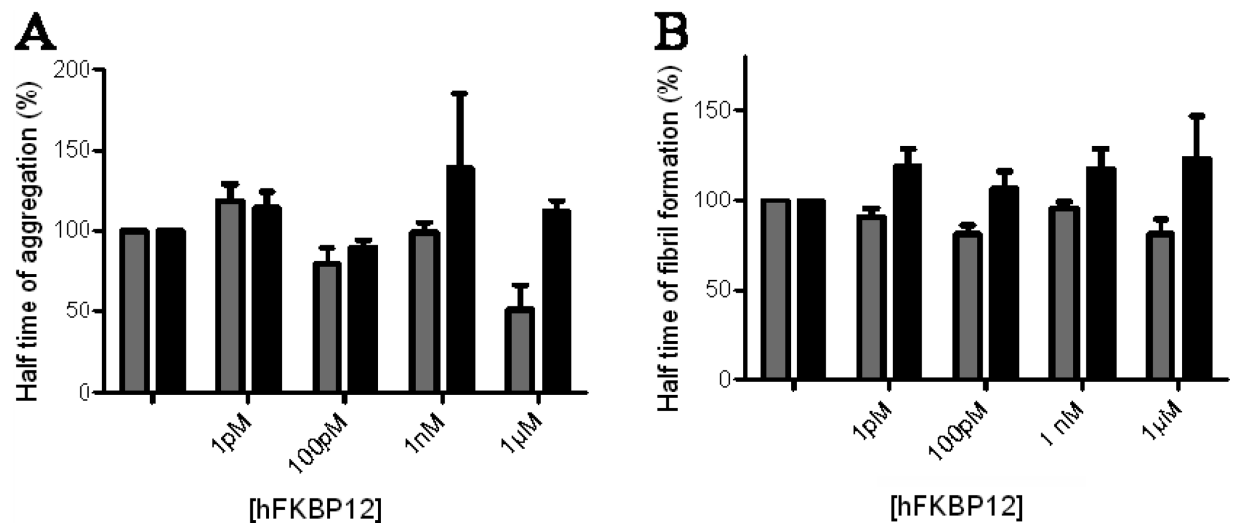

FIGURE 5: Effect of hFKBP12 on the aggregation kinetics of His-WT $\alpha$-syn (gray) and His-PA5 $\alpha$-syn (black). Aggregation kinetics were measured with (A) turbidity and (B) ThT fluorescence. Proteins were incubated at $37^{\circ} \mathrm{C}$ under continuous shaking $(\sim 270 \mathrm{rpm})$.

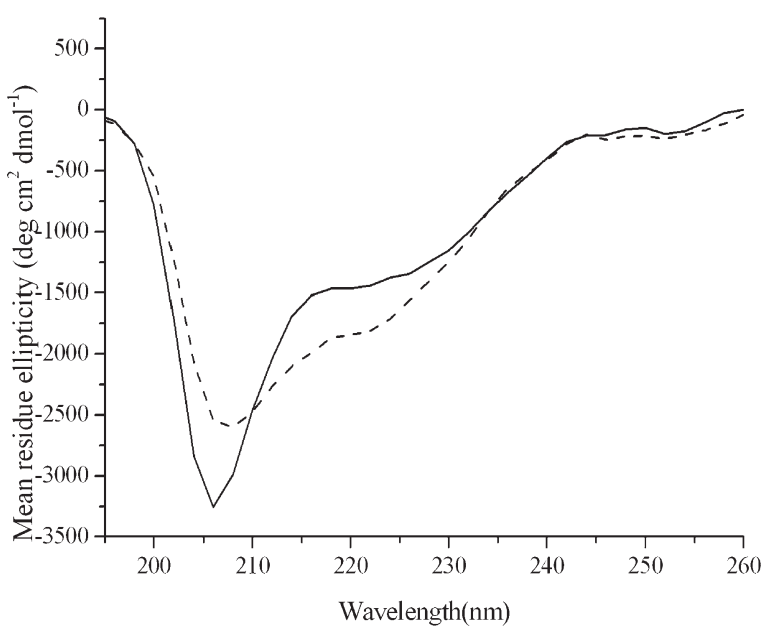

FIgURE 6: Far-UV CD spectrum of His-WT $\alpha$-syn (---) and His-PA 5 $\alpha$-syn (-). Spectra were recorded at room temperature. Compared to the CD spectrum of WT $\alpha$-syn, the minimum around $200 \mathrm{~nm}$ is much less pronounced and shifted to $\sim 205 \mathrm{~nm}$, indicating the following order of $\alpha$-helix content: His-PA ${ }_{5} \alpha$-syn $>$ His-WT $\alpha$-syn $>$ WT $\alpha$-syn.

His-P117A, His-P120A, His-P(108,117)A, His-P(120,128,138)A, and His-PA ${ }_{5} \alpha$-syn. Multiple replacements of Pro do not seem to lead to additional acceleration, and surprisingly enough, triple mutant His-P $(108,117,120) \mathrm{A} \alpha$-syn forms fibrils as fast as His-WT $\alpha$-syn. This suggests that the effect of the Pro mutations is not additive and that the mutation of more than two Pro residues can cancel the effect of the others.

The extent of acceleration is larger for fibril formation than for aggregate formation. This suggests that the conformation of the Pro residues plays a more important role in the process of fibril formation than in early aggregate formation.

It should be remarked that for His-WT $\alpha$-syn the turbidity increase precedes the ThT increase, indicating the formation of non- $\beta$ intermediates, either on or off pathway. For His-PA $\alpha$-syn, fibril formation is accelerated more than aggregation, making the two curves almost coincide (see Figure 2). This seems to suggest that in the latter case intermediates are formed that convert more rapidly into fibrils. The situation is different for mutant $\mathrm{P}(120,128,138) \mathrm{A} \alpha$-syn, in which the turbidity increase is retarded relative to that of WT, while fibril formation is only slightly accelerated. Not all combinations of three Pro mutations lead to this remarkable effect. It is clear that the single and double PA mutations generally create a conformation that is more prone to aggregation and allow a faster intramolecular reorganization leading to the $\beta$-sheet structures necessary for fibril formation, analogous to the "curing" process in polymers.

Loss of the Accelerating Effect of hFKBP12. We also show that the accelerating effect of hFKBP12 is lost in His-PA $\alpha$-syn, supporting the interpretation of the catalytic effect of the enzyme. The accelerating effect at $1 \mu \mathrm{MhFKBP} 12$ was suggested to be a nonenzymatic effect, which would imply that the enzyme would bind at the Pro motif, and mutation of these Pro residues to Ala might abrogate the binding of hFKBP12 to $\alpha$-syn.

An increase in the rate of fibril formation can be seen at both low (picomolar to nanomolar) and high (micromolar) concentrations of hFKBP12. When hFKBP12 is added at higher concentrations, there can be still a binding effect. Addition of hFKBP12 to the His-PA $\mathrm{A}_{5} \alpha$-syn mutant, however, decelerated the aggregation. We cannot easily explain this decelerating effect of hFKBP12 on the fibril formation of His-PA ${ }_{5} \alpha$-syn with the experiments that have been performed. This effect, however, could arise from the binding of $\mathrm{hFKBP} 12$ on a distinct binding site other than the Pro rich sequence, or the stabilization of a conformation that is less active in aggregation.

Role of the Pro Residues in the Conformation of $\alpha$-syn. To study the role of the Pro residues with respect to the conformation of $\alpha$-syn, far-UV CD spectra of His-WT $\alpha$-syn and His-PA $\mathrm{P}_{5} \alpha$-syn were recorded under physiological conditions, before aggregation. The numerical analysis of the measured $\mathrm{CD}$ spectra suggests that His-PA ${ }_{5} \alpha$-syn is more folded than His-WT $\alpha$-syn. On the basis of the obtained results, we can propose the following hypothetical mechanism. It has been shown before that the $\mathrm{C}$-terminus plays a regulating role in the fibril formation of $\alpha$-syn $(16,54)$, and this domain is not incorporated into the core of the fibril $(18,55-57)$. When the charge or hydrophobicity of the C-terminus is changed or the $\mathrm{C}$-terminus is deleted, the rate of aggregation is enhanced in vitro and in cells $(16,50,54,58,59)$. The $\mathrm{C}$-terminal domain of $\alpha$-syn protects the NAC domain with its high charge and low hydrophobicity (16). From our results, we can add that the five proline residues also help to prevent the formation of an aggregationprone conformation. Thus, changing the Pro residues into Ala residues and switching to the all-trans conformation probably extend the C-terminus and reduce the level of shielding of the NAC domain and thus accelerate aggregation and fibril formation.

$\alpha$-syn contains five Pro residues, located in the C-terminal domain of the protein. In principle, the $\mathrm{X}$-Pro peptide bond can be found in both cis and trans conformations in a peptide backbone, which implies that the $\mathrm{C}$-terminus can adopt $2^{5}$ 

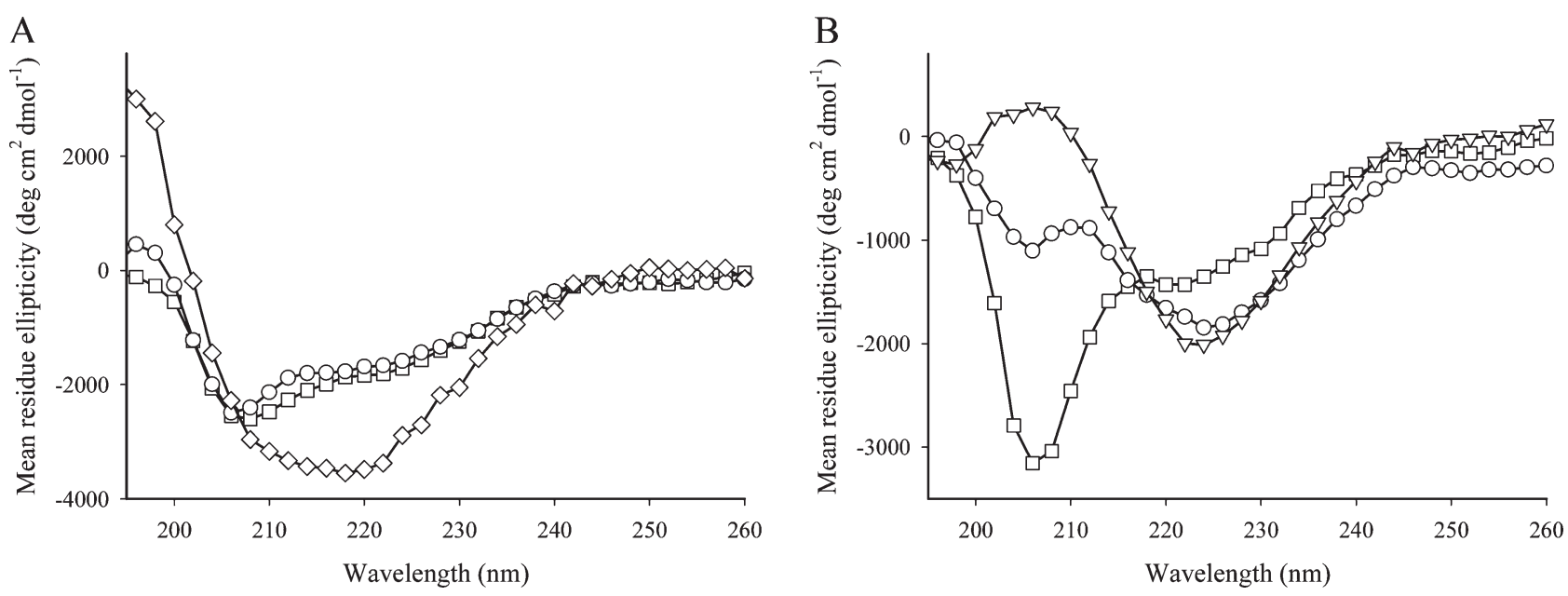

FIGURE 7: Far-UV CD spectra of $\alpha$-syn as a function of the time of aggregation of $70 \mu \mathrm{M}$ protein being stirred continuously $(\sim 500 \mathrm{rpm})$ at $37^{\circ} \mathrm{C}$. For the far-UV CD spectra, samples were taken and cooled to room temperature. (A) His-WT $\alpha$-syn at $0(\square), 25(O)$, and $69 \mathrm{~h}(\diamond)$. (B) His-PA $\alpha$-syn at $0(\square), 21(\bigcirc)$, and $48 \mathrm{~h}(\nabla)$.

possible conformations. Because $\alpha$-syn is an intrinsically unstructured protein, this is theoretically possible. However, because our $\mathrm{CD}$ measurements on the $\mathrm{PA}_{5} \alpha$-syn mutant show that this protein has more structure than WT $\alpha$-syn, it seems likely that at least some Pro residues exist only or mainly in their cis conformation and in this way favor the inhibitory conformation of the C-terminus (20).

\section{ACKNOWLEDGMENT}

We thank Pieter Baatsen (Laboratory for developmental and Molecular genetics) for the help with the EM measurements. We also thank Prof. Vinod Subramaniam for generously providing the pT7-7 expression plasmid.

\section{SUPPORTING INFORMATION AVAILABLE}

Effect of hFKBP12 on the rate of fibril formation of WT and His-WT $\alpha$-syn (Figure S1) and TEM images of His-PA mutants (Figure S2). This material is available free of charge via the Internet at http://pubs.acs.org.

\section{REFERENCES}

1. Chiti, F., and Dobson, C. M. (2006) Protein misfolding, functional amyloid, and human disease. Аnпи. Rev. Biochem. 75, 333-366.

2. Spillantini, M. G., Crowther, R. A., Jakes, R., Hasegawa, M., and Goedert, M. (1998) $\alpha$-Synuclein in filamentous inclusions of Lewy bodies from Parkinson's disease and dementia with lewy bodies. Proc. Natl. Acad. Sci. U.S.A. 95, 6469-6473.

3. Conway, K. A., Lee, S. J., Rochet, J. C., Ding, T. T., Williamson, R. E., and Lansbury, P. T., Jr. (2000) Acceleration of oligomerization, not fibrillization, is a shared property of both $\alpha$-synuclein mutations linked to early-onset Parkinson's disease: Implications for pathogenesis and therapy. Proc. Natl. Acad. Sci. U.S.A. 97, 571-576.

4. Volles, M. J., and Lansbury, P. T., Jr. (2003) Zeroing in on the pathogenic form of $\alpha$-synuclein and its mechanism of neurotoxicity in Parkinson's disease. Biochemistry 42, 7871-7878.

5. Polymeropoulos, M. H., Lavedan, C., Leroy, E., Ide, S. E., Dehejia, A., Dutra, A., Pike, B., Root, H., Rubenstein, J., Boyer, R., Stenroos, E. S., Chandrasekharappa, S., Athanassiadou, A., Papapetropoulos, T., Johnson, W. G., Lazzarini, A. M., Duvoisin, R. C., Di, I. G., Golbe, L. I., and Nussbaum, R. L. (1997) Mutation in the $\alpha$-synuclein gene identified in families with Parkinson's disease. Science 276, 20452047.

6. Kruger, R., Kuhn, W., Muller, T., Woitalla, D., Graeber, M., Kosel, S., Przuntek, H., Epplen, J. T., Schols, L., and Riess, O. (1998) Ala30Pro mutation in the gene encoding $\alpha$-synuclein in Parkinson's disease. Nat. Genet. 18, 106-108.
7. Zarranz, J. J., Alegre, J., Gomez-Esteban, J. C., Lezcano, E., Ros, R., Ampuero, I., Vidal, L., Hoenicka, J., Rodriguez, O., Atares, B., Llorens, V., Gomez Tortosa, E., del Ser, T., Munoz, D. G., and de Yebenes, J. G. (2004) The new mutation, E46K, of $\alpha$-synuclein causes Parkinson and Lewy body dementia. Ann. Neurol. 55, 164-173.

8. Chartier-Harlin, M. C., Kachergus, J., Roumier, C., Mouroux, V., Douay, X., Lincoln, S., Levecque, C., Larvor, L., Andrieux, J., Hulihan, M., Waucquier, N., Defebvre, L., Amouyel, P., Farrer, M., and Destee, A. (2004) $\alpha$-Synuclein locus duplication as a cause of familial Parkinson's disease. Lancet 364, 1167-1169.

9. Singleton, A. B., Farrer, M., Johnson, J., Singleton, A., Hague, S., Kachergus, J., Hulihan, M., Peuralinna, T., Dutra, A., Nussbaum, R., Lincoln, S., Crawley, A., Hanson, M., Maraganore, D., Adler, C., Cookson, M. R., Muenter, M., Baptista, M., Miller, D., Blancato, J., Hardy, J., and Gwinn-Hardy, K. (2003) $\alpha$-Synuclein locus triplication causes Parkinson's disease. Science 302, 841.

10. Kahle, P. J., Haass, C., Kretzschmar, H. A., and Neumann, M. (2002) Structure/function of $\alpha$-synuclein in health and disease: Rational development of animal models for Parkinson's and related diseases. J. Neurochem. 82, 449-457.

11. Feany, M. B., and Bender, W. W. (2000) A Drosophila model of Parkinson's disease. Nature 404, 394-398.

12. Lauwers, E., Beque, D., Van, L. K., Nuyts, J., Bormans, G., Mortelmans, L., Casteels, C., Vercammen, L., Bockstael, O., Nuttin, B., Debyser, Z., and Baekelandt, V. (2007) Non-invasive imaging of neuropathology in a rat model of $\alpha$-synuclein overexpression. Neurobiol. Aging 28, 248-257.

13. Davidson, W. S., Jonas, A., Clayton, D. F., and George, J. M. (1998) Stabilization of $\alpha$-synuclein secondary structure upon binding to synthetic membranes. J. Biol. Chem. 273, 9443-9449.

14. Han, H., Weinreb, P. H., and Lansbury, P. T., Jr. (1995) The core Alzheimer's peptide NAC forms amyloid fibrils which seed and are seeded by $\beta$-amyloid: Is NAC a common trigger or target in neurodegenerative disease? Chem. Biol. 2, 163-169.

15. Giasson, B. I., Murray, I. V., Trojanowski, J. Q., and Lee, V. M. (2001) A hydrophobic stretch of 12 amino acid residues in the middle of $\alpha$-synuclein is essential for filament assembly. J. Biol. Chem. 276, 2380-2386.

16. Hoyer, W., Cherny, D., Subramaniam, V., and Jovin, T. M. (2004) Impact of the acidic C-terminal region comprising amino acids $109-140$ on $\alpha$-synuclein aggregation in vitro. Biochemistry 43, $16233-16242$.

17. McLean, P. J., and Hyman, B. T. (2002) An alternatively spliced form of rodent $\alpha$-synuclein forms intracellular inclusions in vitro: Role of the carboxy-terminus in $\alpha$-synuclein aggregation. Neurosci. Lett. 323, 219-223.

18. Vilar, M., Chou, H. T., Luhrs, T., Maji, S. K., Riek-Loher, D., Verel, R., Manning, G., Stahlberg, H., and Riek, R. (2008) The fold of $\alpha$-synuclein fibrils. Proc. Natl. Acad. Sci. U.S.A. 105, 8637-8642.

19. Qin, Z., Hu, D., Han, S., Hong, D. P., and Fink, A. L. (2007) Role of different regions of $\alpha$-synuclein in the assembly of fibrils. Biochemistry $46,13322-13330$

20. Bertoncini, C. W., Jung, Y. S., Fernandez, C. O., Hoyer, W., Griesinger, C., Jovin, T. M., and Zweckstetter, M. (2005) Release of 
long-range tertiary interactions potentiates aggregation of natively unstructured $\alpha$-synuclein. Proc. Natl. Acad. Sci. U.S.A. 102, 14301435.

21. Zhou, W., Long, C., Reaney, S. H., Di Monte, D. A., Fink, A. L., and Uversky, V. N. (2010) Methionine oxidation stabilizes non-toxic oligomers of $\alpha$-synuclein through strengthening the auto-inhibitory intra-molecular long-range interactions. Biochim. Biophys. Acta 1802, 322-330.

22. Fernandez, C. O., Hoyer, W., Zweckstetter, M., Jares-Erijman, E. A., Subramaniam, V., Griesinger, C., and Jovin, T. M. (2004) NMR of $\alpha$-synuclein-polyamine complexes elucidates the mechanism and kinetics of induced aggregation. EMBO J. 23, 2039-2046.

23. Uversky, V. N., Li, J., and Fink, A. L. (2001) Evidence for a partially folded intermediate in $\alpha$-synuclein fibril formation. J. Biol. Chem. 276, 10737-10744.

24. Nath, S., Meuvis, J., Hendrix, J., Carl, S. A., and Engelborghs, Y. (2010) Early aggregation steps in $\alpha$-synuclein as measured by FCS and FRET: Evidence for a contagious conformational change. Biophys. $J$. 98, 1302-1311.

25. Wood, S. J., Wypych, J., Steavenson, S., Louis, J. C., Citron, M., and Biere, A. L. (1999) $\alpha$-Synuclein fibrillogenesis is nucleation-dependent. Implications for the pathogenesis of Parkinson's disease. J. Biol. Chem. 274, 19509-19512.

26. Gerard, M., Debyser, Z., Desender, L., Kahle, P. J., Baert, J., Baekelandt, V., and Engelborghs, Y. (2006) The aggregation of $\alpha$-synuclein is stimulated by FK506 binding proteins as shown by fluorescence correlation spectroscopy. FASEB J. 20, 524-526.

27. Gerard, M., Debyser, Z., Desender, L., Baert, J., Brandt, I., Baekelandt, V., and Engelborghs, Y. (2008) FK506 binding protein 12 differentially accelerates fibril formation of wild type $\alpha$-synuclein and its clinical mutants A30P or A53T. J. Neurochem. 106, 121-133.

28. Galat, A., and Metcalfe, S. M. (1995) Peptidylproline cis/trans isomerases. Prog. Biophys. Mol. Biol. 63, 67-118.

29. Harding, M. W., Galat, A., Uehling, D. E., and Schreiber, S. L. (1989) A receptor for the immunosuppressant FK506 is a cis-trans peptidylprolyl isomerase. Nature 341, 758-760.

30. Siekierka, J. J., Hung, S. H., Poe, M., Lin, C. S., and Sigal, N. H. (1989) A cytosolic binding protein for the immunosuppressant FK506 has peptidyl-prolyl isomerase activity but is distinct from cyclophilin. Nature 341, 755-757.

31. Parsons, W. H., Sigal, N. H., and Wyvratt, M. J. (1993) FK-506: A novel immunosuppressant. Ann. N.Y. Acad. Sci. 685, 22-36.

32. Nilsson, A., Skold, K., Sjogren, B., Svensson, M., Pierson, J., Zhang, X., Caprioli, R. M., Buijs, J., Persson, B., Svenningsson, P., and Andren, P. E. (2007) Increased striatal mRNA and protein levels of the immunophilin FKBP-12 in experimental Parkinson's disease and identification of FKBP-12-binding proteins. J. Proteome Res. 6, 3952-3961.

33. Avramut, M., and Achim, C. L. (2002) Immunophilins and their ligands: Insights into survival and growth of human neurons. Physiol. Behav. 77, 463-468.

34. Sugata, H., Matsuo, K., Nakagawa, T., Takahashi, M., Mukai, H., Ono, Y., Maeda, K., Akiyama, H., and Kawamata, T. (2009) A peptidyl-prolyl isomerase, FKBP12, accumulates in Alzheimer neurofibrillary tangles. Neurosci. Lett. 459, 96-99.

35. Gerard, M., Deleersnijder, A., Daniels, V., Schreurs, S., Munck, S., Reumers, V., Pottel, H., Engelborghs, Y., Van den, H. C., Taymans, J. M., Debyser, Z., and Baekelandt, V. (2010) Inhibition of FK506 Binding Proteins Reduces $\alpha$-Synuclein Aggregation and Parkinson's Disease-like Pathology. J. Neurosci. 30, 2454-2463.

36. Lu, P. J., Wulf, G., Zhou, X. Z., Davies, P., and Lu, K. P. (1999) The prolyl isomerase Pin 1 restores the function of Alzheimer-associated phosphorylated tau protein. Nature 399, 784-788.

37. Ryo, A., Togo, T., Nakai, T., Hirai, A., Nishi, M., Yamaguchi, A., Suzuki, K., Hirayasu, Y., Kobayashi, H., Perrem, K., Liou, Y. C., and Aoki, I. (2006) Prolyl-isomerase Pin1 accumulates in lewy bodies of parkinson disease and facilitates formation of $\alpha$-synuclein inclusions. J. Biol. Chem. 281, 4117-4125.

38. van Raaij, M. E., Segers-Nolten, I. M., and Subramaniam, V. (2006) Quantitative morphological analysis reveals ultrastructural diversity of amyloid fibrils from $\alpha$-synuclein mutants. Biophys. J. 91, L96-L98.
39. Kullertz, G., Luthe, S., and Fischer, G. (1998) Semiautomated microtiter plate assay for monitoring peptidylprolyl cis/trans isomerase activity in normal and pathological human sera. Clin. Chem. 44, 502-508.

40. Cohlberg, J. A., Li, J., Uversky, V. N., and Fink, A. L. (2002) Heparin and other glycosaminoglycans stimulate the formation of amyloid fibrils from $\alpha$-synuclein in vitro. Biochemistry 41, 1502-1511.

41. Nielsen, L., Khurana, R., Coats, A., Frokjaer, S., Brange, J., Vyas, S., Uversky, V. N., and Fink, A. L. (2001) Effect of environmental factors on the kinetics of insulin fibril formation: Elucidation of the molecular mechanism. Biochemistry 40, 6036-6046.

42. Johnson, W. C. (1999) Analyzing protein circular dichroism spectra for accurate secondary structures. Proteins 35, 307-312.

43. Lobley, A., Whitmore, L., and Wallace, B. A. (2002) DICHROWEB: An interactive website for the analysis of protein secondary structure from circular dichroism spectra. Bioinformatics 18, 211-212.

44. Whitmore, L., and Wallace, B. A. (2004) DICHROWEB, an online server for protein secondary structure analyses from circular dichroism spectroscopic data. Nucleic Acids Res. 32, W668-W673.

45. Li, J., Uversky, V. N., and Fink, A. L. (2001) Effect of familial Parkinson's disease point mutations A30P and A53T on the structural properties, aggregation, and fibrillation of human $\alpha$-synuclein. Biochemistry 40, 11604-11613.

46. Li, J., Uversky, V. N., and Fink, A. L. (2002) Conformational behavior of human $\alpha$-synuclein is modulated by familial Parkinson's disease point mutations A30P and A53T. Neurotoxicology 23, 553567.

47. LeVine, H., III (1993) Thioflavine T interaction with synthetic Alzheimer's disease $\beta$-amyloid peptides: Detection of amyloid aggregation in solution. Protein Sci. 2, 404-410.

48. Spillantini, M. G., Schmidt, M. L., Lee, V. M., Trojanowski, J. Q., Jakes, R., and Goedert, M. (1997) $\alpha$-Synuclein in Lewy bodies. Nature 388, 839-840.

49. Tradler, T., Stoller, G., Rucknagel, K. P., Schierhorn, A., Rahfeld, J. U., and Fischer, G. (1997) Comparative mutational analysis of peptidyl prolyl cis/trans isomerases: Active sites of Escherichia coli trigger factor and human FKBP12. FEBS Lett. 407, 184-190.

50. Hoyer, W., Antony, T., Cherny, D., Heim, G., Jovin, T. M., and Subramaniam, V. (2002) Dependence of $\alpha$-synuclein aggregate morphology on solution conditions. J. Mol. Biol. 322, 383-393.

51. Outeiro, T. F., Klucken, J., Bercury, K., Tetzlaff, J., Putcha, P., Oliveira, L. M., Quintas, A., McLean, P. J., and Hyman, B. T. (2009) Dopamine-induced conformational changes in $\alpha$-synuclein. PLoS One 4, e6906.

52. Zscherp, C., Aygun, H., Engels, J. W., and Mantele, W. (2003) Effect of proline to alanine mutation on the thermal stability of the all- $\beta$-sheet protein Tendamistat. Biochim. Biophys. Acta 1651, 139145 .

53. Eyles, S. J., and Gierasch, L. M. (2000) Multiple roles of prolyl residues in structure and folding. J. Mol. Biol. 301, 737-747.

54. Murray, I. V., Giasson, B. I., Quinn, S. M., Koppaka, V., Axelsen, P. H., Ischiropoulos, H., Trojanowski, J. Q., and Lee, V. M. (2003) Role of $\alpha$-synuclein carboxy-terminus on fibril formation in vitro. Biochemistry 42, 8530-8540.

55. Chen, M., Margittai, M., Chen, J., and Langen, R. (2007) Investigation of $\alpha$-synuclein fibril structure by site-directed spin labeling. J. Biol. Chem. 282, 24970-24979.

56. Del, M. C., Greenbaum, E. A., Mayne, L., Englander, S. W., and Woods, V. L., Jr. (2005) Structure and properties of $\alpha$-synuclein and other amyloids determined at the amino acid level. Proc. Natl. Acad. Sci. U.S.A. 102, 15477-15482.

57. Der-Sarkissian, A., Jao, C. C., Chen, J., and Langen, R. (2003) Structural organization of $\alpha$-synuclein fibrils studied by site-directed spin labeling. J. Biol. Chem. 278, 37530-37535.

58. Opazo, F., Krenz, A., Heermann, S., Schulz, J. B., and Falkenburger, B. H. (2008) Accumulation and clearance of $\alpha$-synuclein aggregates demonstrated by time-lapse imaging. J. Neurochem. 106, 529-540.

59. Ulusoy, A., Febbraro, F., Jensen, P. H., Kirik, D., and RomeroRamos, M. (2010) Co-expression of C-terminal truncated $\alpha$-synuclein enhances full-length $\alpha$-synuclein-induced pathology. Eur. J. Neurosci. $32,409-422$. 